\title{
The Effect of Aluminum Additions on the Oxidation Resistance of $\mathrm{U}_{3} \mathrm{Si}_{2}$
}

\author{
E.Sooby Wood ${ }^{\mathrm{a}, *}$, J.T. White ${ }^{\mathrm{a}}$, A.T. Nelson ${ }^{\mathrm{a}}$ \\ ${ }^{a}$ Materials Science and Technology Division, Los Alamos National Laboratory, Los \\ Alamos, NM
}

\begin{abstract}
The effect of aluminum additions to $\mathrm{U}_{3} \mathrm{Si}_{2}$ is investigated as a means to improve the oxidation resistance of this nuclear fuel form. Four U-Si-Al compositions have been synthesized and characterized using scanning electron microscopy, energy dispersive spectroscopy, and x-ray diffraction. The onsets of breakaway oxidation are identified in air thermal ramp tests using thermogravimetric analysis. The final oxidation products following $1000^{\circ} \mathrm{C}$ air exposure are identified using x-ray diffraction and compared to those of $\mathrm{UO}_{2}$ and $\mathrm{U}$ metal oxidized in the same manner. Thermogravimetric data acquired in this study indicates that increasing amounts of $\mathrm{Al}$ in $\mathrm{U}_{3} \mathrm{Si}_{2}$ further delays the onset of breakaway oxidation, providing enhanced oxidation resistance in air. $\mathrm{Al}_{2} \mathrm{O}_{3}$ formation on $\mathrm{U}_{3} \mathrm{Al}_{2} \mathrm{Si}_{3}$ is observed following a heat treatment performed at $500{ }^{\circ} \mathrm{C}$ in air, demonstrating the potential of $\mathrm{Al}$ additions to improve the oxidation resistance of $\mathrm{U}_{3} \mathrm{Si}_{2}$.
\end{abstract}

${ }^{*}$ Corresponding author

Email address: sooby@lanl.gov (E.Sooby Wood)

Preprint submitted to Journal of Nuclear Materials

January 27, 2017

(C) 2017. This manuscript version is made available under the Elsevier user license http://www.elsevier.com/open-access/userlicense/1.0/ 


\section{Introduction}

The U-Si system presents multiple candidate nuclear fuel compounds, including $\mathrm{U}_{3} \mathrm{Si}, \mathrm{U}_{3} \mathrm{Si}_{2}$, USi, and $\mathrm{U}_{3} \mathrm{Si}_{5}$. All provide increased thermal conductivity compared to conventional oxide fuel.[1-4] $\mathrm{U}_{3} \mathrm{Si}_{2}$ is receiving the most attention for deployment as a drop-in fuel form to improve the performance of commercial light water reactors due primarily to its increased U density compared to reference $\mathrm{UO}_{2}$, improved thermal conductivity, and limited but demonstrated record of satisfactory service as a nuclear fuel. However, it is susceptible to oxidation. Existing data suggests that $\mathrm{U}_{3} \mathrm{Si}_{2}$ would be, at best, neutral to $\mathrm{UO}_{2}$ and provide no additional accident tolerance with respect to oxidation resistance. [5-8]

Small additions of alloying elements can increase the oxidation tolerance of many materials. For example, $\mathrm{Cr}$ and $\mathrm{Al}$ are often added to steels to retard degradation in oxidizing atmospheres by forming oxide scales that act as diffusion barriers to continued oxidation. $\mathrm{UO}_{2}$ formation is thermodynamically favored over $\mathrm{SiO}_{2}$ in $\mathrm{U}_{3} \mathrm{Si}_{2}$ and leads to the eventual pulverization of the compound.[8] An alloying element which would oxidize preferentially to $\mathrm{U}$ and yield a passivating oxide could delay $\mathrm{UO}_{2}$ formation and potentially delay the onset of breakaway oxidation which inevitably leads to rapid pulverization.

An Ellingham Diagram, shown in Figure 1, was constructed to elucidate potential alloying additions to the U-Si systems that would preferentially oxidize relative to U.[9] The change in Gibbs Free Energy $(\Delta \mathrm{G})$ for $\mathrm{Al}$ to form $\mathrm{Al}_{2} \mathrm{O}_{3}$ is more negative than that for $\mathrm{U}$ to form $\mathrm{UO}_{2}$ below $600^{\circ} \mathrm{C}$. Given the well known ability of $\mathrm{Al}_{2} \mathrm{O}_{3}$ to act as a passivating oxide such that base material remains shielded from the oxidizing specie, $\mathrm{Al}$ was chosen as an initial elemental addition for study of its effect on oxidation of $\mathrm{U}_{3} \mathrm{Si}_{2}$. This work presents the results of initial investigations of the ability of dilute $\mathrm{Al}$ additions to forestall breakaway oxidation in $\mathrm{U}_{3} \mathrm{Si}_{2}$. 


\section{Background}

U-Si-Al fuel forms have been explored in the past. The primary applications were dispersion/plate fuel concepts, in which $\mathrm{U}_{3} \mathrm{Si}_{2}, \mathrm{U}_{3} \mathrm{Si}_{2}$, and/or $\mathrm{UAl}_{2}$ were distributed in an Al plate.[10, 11] Through a series of experimental efforts which included high temperature annealing, oxidation, and diffusion couple tests, it was found that non-equilibrium compositions of U-Si-Al (e.g. $\mathrm{U}_{3}(\mathrm{Si}, \mathrm{Al})$ ) resulted in multi-phase composites after high temperature exposure. $[12,13]$ However, some reports indicate that these phases swelled less than $\mathrm{U}_{3} \mathrm{Si}$ under irradiation and displayed little to no cracking during post irradiation examination. $[14,15]$ In addition, the $\mathrm{UAl}_{2}$ phase was reported to more readily accommodate fission product gases such as $\mathrm{Kr}$ and Xe, making it less prone to fission gas swelling when compared to non-equilibrium composition $\mathrm{U}_{3} \mathrm{AlSi}$.[16] Boiling water corrosion tests were performed on a single non-equilibrium composition. The researchers exposed the candidate plate fuel to boiling water for several hours and then monitored the water bath for increased radioactivity following exposure. No increased activity was detected in the water bath following the experiment; oxidation behavior was not investigated.[10]

The ternary phase diagram for the U-Si-Al system has been investigated to limited extent.[17] The $\mathrm{U}_{3} \mathrm{Al}_{2} \mathrm{Si}_{3}$ equilibrium compound with a $\mathrm{U}$ density of $7.45 \mathrm{~g} / \mathrm{cm}^{3}$ provides a similar fissile density to $\mathrm{U}_{3} \mathrm{Si}_{5}\left(7.57 \mathrm{~g} / \mathrm{cm}^{3}\right)$ and $\mathrm{U}_{3} \mathrm{O}_{8}\left(7.28 \mathrm{~g} / \mathrm{cm}^{3}\right)$. Referring to the published phase diagram reproduced in Figure 2, the compound labeled $\mathrm{U}_{3} \mathrm{Al}_{2} \mathrm{Si}_{3}$ does not correspond to such a composition. Rather, this composition should be $\mathrm{U}_{2} \mathrm{AlSi}_{2}$. $\mathrm{U}_{3} \mathrm{Al}_{2} \mathrm{Si}_{3}$ is calculated to be on the line between $\mathrm{U}_{2} \mathrm{AlSi}_{2}$ and UAlSi. This discrepancy in the phase diagram makes it difficult to discern if $\mathrm{U}_{3} \mathrm{Al}_{2} \mathrm{Si}_{3}$ is truly an equilibrium compound. Rogi et al do not address this inconsistency in the study used to assemble this part of the phase diagram.[18] Nevertheless, $\mathrm{U}_{3} \mathrm{Al}_{2} \mathrm{Si}_{3}$ (i.e. a composition corresponding to $\mathrm{U}_{.375} \mathrm{Al}_{25} \mathrm{Si}_{.375}$ ) is studied here as the upper bound for $\mathrm{Al}$ additions to $\mathrm{U}_{3} \mathrm{Si}_{2}$ with the goal of forming $\mathrm{Al}_{2} \mathrm{O}_{3}$ to provide a passive oxide layer while retaining a $\mathrm{U}$ density amenable to service as a nuclear reactor fuel.

The maximum solubility of $\mathrm{Al}\left(1.8\right.$ at $\%$ at $\left.900^{\circ} \mathrm{C}\right)$ within a U-Si matrix was chosen to set the lower limit of $\mathrm{Al}$ addition.[17] Therefore the low-doped $\mathrm{Al}$ composition investigated here incorporates $1.8 \mathrm{at} \% \mathrm{Al}$ and is nominally 

66 are also synthesized to conclude the present study.

\footnotetext{
${ }^{1}$ Each composition is normalized to three moles $U$ for consistency, however these should not necessarily be interpreted as single phase structures.
} 


\section{Experimental}

\subsection{Material Preparation}

Each composition was synthesized by arc melting of the pure metals. A tri-arc furnace (Centorr Vacuum Industries, Nashua, NH, USA) was used. The starting partial pressure of $\mathrm{O}_{2}\left(\mathrm{pO}_{2}\right)$ for each melt was $<10^{-12}$ parts per million (ppm) as verified by the $\mathrm{O}_{2}$ sensors located on both the inlet and exhaust of the system. An internal Ti getter, maintained in the molten state during synthesis of all compositions, reduced the $\mathrm{pO}_{2}$ to $<10^{-19} \mathrm{ppm}$ on the exhaust of the arc melter. $\mathrm{U}_{3} \mathrm{Al}_{2} \mathrm{Si}_{3}$ and $\mathrm{U}_{3} \mathrm{Si}_{2}+1.8$ at\% $\mathrm{Al}$ were synthesized via arc melting uranium metal discs (approx. 99.5\% pure) that were ground to remove surface oxide and weighed. Silicon metal pieces (Cerac 99.999\% pure, 3-6 mm pieces) and aluminum wire (Alfa Aesar 99.999\% pure, $1 \mathrm{~mm}$ diameter) were sectioned and weighed to match the projected wt $\%$ necessary to synthesize the target compositions according to the $U$ weight in each button. For each composition investigated here, the arc melted button was melted and flipped five times to homogenize the chemical composition of the melt.

In order to minimize oxide contamination during synthesis of the $\mathrm{U}_{3} \mathrm{Si}_{2} \mathrm{Al}_{0.75}$ and $\mathrm{U}_{3} \mathrm{Si}_{2} \mathrm{Al}_{1.25}$ compositions, the arc melter was placed in an Ar glove box with $\mathrm{pO}_{2}$ and $\mathrm{pH}_{2} \mathrm{O}<0.1 \mathrm{ppm}$. The same $\mathrm{Si}$ and $\mathrm{Al}$ stocks were used in this arc melt, and U metal rods (99.9+\% purity, AeroJet Rocketdyne, Jonesborough, TN, USA) were ground to remove surface oxides. Inductively coupled plasma-mass spectrometry (ICP-MS) analysis performed by MCL Inc. revealed no contamination by rare earth or transition metals greater than either the detection limits or $10 \mu \mathrm{g} / \mathrm{g}$.

Material loss during arc melting can cause compositional error. One can determine the likely cause of this mass loss is either splintering of the button on cooling or volatilization of $\mathrm{Al}$ or Si. Table 1 reports the target compositions along with the resulting stoichiometries assuming all of the mass loss is due to $\mathrm{Al}$ volatilization, which is the most conservative estimate of compositional error. This uncertainty should not affect the results of assessing relative increases in $\mathrm{Al}$ content to the oxidation resistance of $\mathrm{U}_{3} \mathrm{Si}_{2}$. However, when arc melting equilibrium compositions, either additional $\mathrm{Al}$ and Si should be included prior to melt to compensate for the anticipated loss, or a melt process should be devised to avoid volatilization. Si volatilization has been observed in the synthesis of U-Si compounds in the past where additional Si was incorporated in the melt.[1-4] 


\subsection{Compositional Analysis}

X-ray diffraction (XRD) and scanning electron microscopy (SEM) analysis were used to determine compositional purity and phase identification for each of the as-melted compositions. No additional solutionization heat treatments or metallurgical processing were employed for any of these compositions prior to analysis and measurement. The samples used in both the SEM characterization and oxidation testing were fracture pieces from the as melted buttons, and the material used for XRD analysis was ground from button fragments.

XRD was employed to analyze the ground, as-melted buttons using a Bruker XRD (D2 Phaser, Bruker AXS, Madison, WI, USA). The samples were prepared in an Ar glove box and encapsulated to avoid oxidation. A two theta range of $10-90^{\circ}, 0.01^{\circ}$ step size, and $2 \mathrm{~s}$ dwell time were used for all samples. XRD analysis of the resulting oxides following oxidation testing used the same parameters.

A Phenom ProX SEM (Phenom-World, Phoenix, Arizona, USA) equipped with a backscatter electron detector and energy dispersive spectrometer (EDS) was used to image and analyze the as melted compositions. Three button fragments were potted in epoxy and ground/polished to $3 \mu \mathrm{m}$ using a combination of $\mathrm{SiC}$ grinding discs and diamond suspension for each as-melted composition. A backscatter detector was used to image the phase contrast in each sample.

\subsection{Thermogravimetric Analysis}

The mass of each fracture sample was measured in an Ar glove box using a balance (Mettler-Toledo, Columbus, Ohio) calibrated to ${ }_{-}^{+} 0.1 \mathrm{mg}$. The sample was placed in an $\mathrm{Al}_{2} \mathrm{O}_{3}$ crucible. A commercial simultaneous thermal analyzer (STA 449 F3, Netzsch Instruments, Selb, Germany) was used to measure the mass gain during thermal ramp oxidation tests. A thermocouple calibration was performed using $\mathrm{Ni}, \mathrm{Au}, \mathrm{Ag}, \mathrm{Al}$, and $\mathrm{Zn}$ melt point standards (6.223.5-91.3, Netzsch, Selb, Germany) prior to this experimental effort, and both the thermocouple correction and a baseline correction file were incorporated in each oxidation test using the Netzsch software. The compositions were ramped in a synthetic air atmosphere $(80 \% \mathrm{Ar}, 20 \% \mathrm{O} 2)$ at $5{ }^{\circ} \mathrm{C} / \mathrm{min}$ to $1100{ }^{\circ} \mathrm{C}$, held for $15 \mathrm{~min}$, and then cooled at $20^{\circ} \mathrm{C} / \mathrm{min}$ in a manner used previously to study oxidation of U-Si compounds. [8] 


\section{Results and Discussion}

\subsection{Compositional Analysis}

The XRD diffraction pattern for the ground, as-melted $\mathrm{U}_{3} \mathrm{Si}_{2}+1.8 \mathrm{at} \% \mathrm{Al}$ button is displayed in Figure 3. The collected XRD pattern is in good agreement with the reference $\mathrm{U}_{3} \mathrm{Si}_{2}$ pattern, however there are discrepancies that were not resolved during phase analysis when compared to other silicide and aluminide phases. The peak heights at higher angle, $2 \theta>50^{\circ}$, are inconsistent with the reference pattern relative intensities. This could be due to a secondary phase formed on cooling, which was identified in SEM analysis, or lattice augmentations caused by the aluminum addition.

Multiple phases were identified in the $\mathrm{U}_{3} \mathrm{Si}_{2} \mathrm{Al}_{0.75}$ composition, which is to be expected for this non-equilibrium composition. It is composed primarily of $\mathrm{U}_{3} \mathrm{Si}_{2}$ with some $\mathrm{Al}$ containing phases as displayed in Figure 3.

$\mathrm{U}_{3} \mathrm{Si}_{2} \mathrm{Al}_{1.25}$ was also identified as multiphase, which is again to be expected for this non-equilibrium composition. It is composed primarily of $\mathrm{U}_{3} \mathrm{Si}_{2}$ and $\mathrm{U}_{3} \mathrm{Al}_{2} \mathrm{Si}_{3}$ with some unidentified phase present as displayed in Figure 3.

Lastly, Figure 3 displays the x-ray diffraction pattern for the as melted $\mathrm{U}_{3} \mathrm{Al}_{2} \mathrm{Si}_{3}$ composition. Though there is good agreement with the reference pattern for $\mathrm{U}_{3} \mathrm{Al}_{2} \mathrm{Si}_{3}$, there are also a number of peaks which match an $\mathrm{Al}$ rich, Si-poor phase, $\mathrm{U}\left(\mathrm{Si}_{0.44} \mathrm{Al}_{1.56}\right)$. In addition there are three small, unidentified peaks at $2 \theta=27,30$, and $35^{\circ}$.

Characteristic SEM micrographs of these four compositions are displayed in Figure 4. The secondary phases which have segregated in each of these compositions may have done so upon cooling during the arc melting process. While each of these compositions have multiple phases, the $\mathrm{U}_{3} \mathrm{Al}_{2} \mathrm{Si}_{3}$ composition is comprised of primarily two phases in agreement with the XRD data displayed in Figure 3. $\mathrm{U}_{3} \mathrm{Si}_{2}+1.8 \mathrm{at} \% \mathrm{Al}$ appears mostly single phase in Figure 4, with only a small amount of phase segregation. The two secondary phases identified were only found together during SEM analysis. These appeared as a lighter and darker phase, the darker being an Al-rich and the lighter a U-rich phase. This is also characteristic of phase segregation during cooling. The two intermediate compositions have at least three phases present as observed in SEM analysis, and while two phases contain all three of the elemental constituents per the XRD analysis, it is likely that the minor phases are U-Si or U-Al binary compounds. EDS analysis was able to identify Si and Al-rich areas, however no area was found totally devoid of all 
three elements; this is thought to be due to the interaction volume during EDS analysis.

A solutionization heat treatment could prove beneficial in homogenizing two of these compositions from multiphase to single phase. It is reported that $1.8 \mathrm{at} \% \mathrm{Al}$ should be soluble in $\mathrm{U}_{3} \mathrm{Si}_{2}$ at $900^{\circ} \mathrm{C}$, though it may have segregated on cooling. Also it is reported that $\mathrm{U}_{3} \mathrm{Al}_{2} \mathrm{Si}_{3}$ is an equilibrium compound although uncertainty exists as discussed earlier. Therefore, using a heat treatment to allow homogenization of the secondary phases present in these two samples could result in a single phase material, where the rapid and nonuniform (the outer portions of the button tend to cool first) cooling of the arc melting process caused segregation. Phase segregation should not affect the results of the present study which investigates the relative oxidation resistance of $\mathrm{U}-\mathrm{Si}-\mathrm{Al}$ compositions with increasing $\mathrm{Al}$ content.

\subsection{Thermogravimetric Analysis}

Table 1 presents the calculated onsets of breakaway oxidation as identified by the Netzsch Proteus software and the terminal oxidation, which is the percentage mass gain measured following oxidation.[8] Figure 5 displays the thermograms used to calculate the onsets of breakaway oxidation. This data is normalized to the theoretical mass gain expected for each composition assuming $\mathrm{U}_{3} \mathrm{O}_{8}, \mathrm{SiO}_{2}$, and $\mathrm{Al}_{2} \mathrm{O}_{3}$ are the final oxidation products. The shoulder present in the TG data for $\mathrm{U}_{3} \mathrm{Si}_{2}$ and $\mathrm{U}_{3} \mathrm{Si}_{2}+1 / 8 \mathrm{at} \% \mathrm{Al}$ is characteristic of U-Si oxidation. [8] The terminal oxidation mass gain of each compositions falls short of the theoretical maximum for all U-Si-Al compositions tested here, though a plateau is reached for each sample. It should be noted that $\mathrm{U}_{3} \mathrm{Si}_{2}$ without $\mathrm{Al}$ addition suffers breakaway oxidation and pulverization at a temperature comparable to $\mathrm{UO}_{2}$ during air oxidation. However these screening test atmospheres are not representative of either reactor operation or design basis accident conditions. Steam and autoclave testing are still necessary to understand how they will behave in an environment more characteristic of normal operating occurrences (e.g. 'leaker') or an off-normal reactor scenario.

Figure 5 and Table 1 indicate that the onset of breakaway oxidation is further delayed by increasing $\mathrm{Al}$ content. However, given the multiphase nature of the intermediate compositions, $\mathrm{U}_{3} \mathrm{Si}_{2} \mathrm{Al}_{0.75 / 1.25}$, it is possible to capture more of one phase in a TG sample than another. The delayed onsets reported here were reproduced during testing within the error of this 
technique, which has been shown to be minimally sensitive to ramp rate and sample geometry.[8]

\subsection{X-Ray Diffraction Analysis of Oxidation products}

$\mathrm{X}$-ray diffraction patterns for the oxide products formed during thermal ramp oxidation of these compositions compared to $\mathrm{U}$ metal are displayed in Figure 6. The primary phase present is $\mathrm{U}_{3} \mathrm{O}_{8}$ with a small amount of $\mathrm{UO}_{2}$. This is typical of air oxidation of U-Si compounds. [8] Since U metal accounts for approximately $90 \%$ of the weight percent, it is expected that $\mathrm{U}_{3} \mathrm{O}_{8}$ would dominate the final oxidation product of these compositions. Si and Al oxidation products were not identified in this analysis; however the lack of $\mathrm{Si} / \mathrm{SiO}_{2}$ appears to be characteristic of these types of oxidation test. [8, 7] $\mathrm{Al}_{2} \mathrm{O}_{3}$ was identified in cross sectional SEM analysis of a partially oxidized $\mathrm{U}_{3} \mathrm{Al}_{2} \mathrm{Si}_{3}$ sample, indicating that XRD is not an exhaustive method of analysis to identify the products formed during oxidation of these materials.

\subsection{Scanning Electron Microscopy analysis of Oxide formation}

The cross sectioned and polished surface of the as-melted $\mathrm{U}_{3} \mathrm{Al}_{2} \mathrm{Si}_{3}$ composition is displayed in the left image of Figure 7. This composition proved to be multi-phased, primarily $\mathrm{U}_{3} \mathrm{Al}_{2} \mathrm{Si}_{3}$ with some $\mathrm{Al}$ and $\mathrm{Si}$ containing secondary phase. The oxidized surface of this sample is displayed in the right image of Figure 7 following a $500^{\circ} \mathrm{C}$ isothermal oxidation heat treatment.

The sample was potted in epoxy, cross sectioned, and polished. During SEM investigation, EDS was utilized as a qualitative elemental analysis method; no elemental standards were employed, and therefore the resulting elemental analysis cannot be quantified. It was observed that only $\mathrm{Al}$ and $\mathrm{O}$ are located on the outer surface and along cracks, which propagated throughout the button fragment. The oxide identified is likely $\mathrm{Al}_{2} \mathrm{O}_{3}$. The SEM analysis is displayed along with and EDS map in Figure 8. The $\mathrm{Al}_{2} \mathrm{O}_{3}$ layer appears to be fairly uniform in thickness throughout the sample edges and cracked portions. $\mathrm{U}$ is not mapped here since it dominates throughout the EDS map.

The presence of $\mathrm{Al}$ along the cracks of the button fragment demonstrates that $\mathrm{Al}_{2} \mathrm{O}_{3}$ has indeed formed preferentially to $\mathrm{UO}_{2}$. In previous investigations, $\mathrm{UO}_{2}$ was identified along the edges and cracks of button fragments. $\mathrm{UO}_{2}$ is known to be a non-passivating oxide, readily allowing the diffusion of oxygen through the oxide layer, resulting in further oxidation of the material 
247 and eventual pulverization. [8] It is likely that the preferential formation of ${ }_{248} \mathrm{Al}_{2} \mathrm{O}_{3}$ is the cause of the delay in the onset of breakaway oxidation.

249 The heat treatment used to form the $\mathrm{Al}_{2} \mathrm{O}_{3}$ layer was repeated and the 250 isothermal hold at $500^{\circ} \mathrm{C}$ was continued until the sample reached its ter251 minal oxidation. The resulting material was a pulverized oxide. Therefore 252 the layer formed under these conditions is not fully passivating, however the 253 preferential formation of $\mathrm{Al}_{2} \mathrm{O}_{3}$ indicates that engineering a protective layer 254 is feasible. It is possible that $\mathrm{Al}_{2} \mathrm{O}_{3}$ is not coarsening at $500^{\circ} \mathrm{C}$, and a higher 255 temperature oxidation treatment is necessary to produce a passivating sur256 face layer on the U-Si-Al composition. 


\section{Conclusions}

The effect of $\mathrm{Al}$ additions on oxidation resistance of $\mathrm{U}_{3} \mathrm{Si}_{2}$ has been investigated. Thermogravimetric analysis has indicated that increasing amounts of $\mathrm{Al}$ in $\mathrm{U}_{3} \mathrm{Si}_{2}$ further delays the onset of breakaway oxidation in air. Scanning electron microscopy paired with energy dispersive spectroscopy has revealed that an $\mathrm{Al}_{2} \mathrm{O}_{3}$ layer forms at $500^{\circ} \mathrm{C}$. Though this layer was not found to be passivating in this study, it demonstrates the potential for this approach to increase the oxidation resistance of $\mathrm{U}_{3} \mathrm{Si}_{2}$. Further work is necessary to assess if a passivating layer can be formed on these materials.

\section{Acknowledgments}

The authors would like to acknowledge Darrin Byler and Christopher Grote of the Materials Science and Technology Division at LANL for their technical assistance in this experimental effort. This work was conducted at Los Alamos National Laboratory (LANL) under the National Nuclear Security Administration contract DE-AC52-06NA25396 and supported by the U.S. Department of Energy, Office of Nuclear Energy Fuel Cycle Research and Development program and the LANL Seaborg Institute for Actinide Science. 


\section{References}

[1] J. White, A. Nelson, D. Byler, J. Valdez, K. McClellan, Thermophysical properties of $\mathrm{U}_{3} \mathrm{Si}$ to $1150 \mathrm{~K}$, Journal of Nuclear Materials 452 (13) (2014) 304 - 310. doi:http://dx.doi.org/10.1016/j.jnucmat.2014.05.037.

[2] J. White, A. Nelson, J. Dunwoody, D. Byler, D. Safarik, K. McClellan, Thermophysical properties of $\mathrm{U}_{3} \mathrm{Si}_{2}$ to 1773 K, Journal of Nuclear Materials 464 (2015) 275 - 280. doi:http://dx.doi.org/10.1016/j.jnucmat.2015.04.031.

[3] J. White, A. Nelson, J. Dunwoody, D. Byler, K. McClellan, Thermophysical properties of USi to 1673K, Journal of Nuclear Materials 471 (2016) 129 - 135. doi:http://dx.doi.org/10.1016/j.jnucmat.2016.01.013.

[4] J. White, A. Nelson, D. Byler, D. Safarik, J. Dunwoody, K. McClellan, Thermophysical properties of $\mathrm{U}_{3} \mathrm{Si}_{5}$ to 1773 K, Journal of Nuclear Materials 456 (2015) 442 - 448. doi:http://dx.doi.org/10.1016/j.jnucmat.2014.10.021.

[5] L. D. Loch, G. B. Engle, M. J. Snyder, W. H. Duckworth, Survey of refractory uranium compounds, Tech. rep., Battelle Memorial Inst., Columbus, Ohio (1956).

[6] M. J. Snyder, W. H. Duckworth, Properties of some refractory uranium compounds, Tech. rep., BMI (Battelle Memorial Institute (United States)) (1957).

[7] M. Feraday, The oxidation, hydriding and aqueous corrosion of $\mathrm{U}_{3} \mathrm{Si}$ alloys, Tech. rep., Atomic Energy of Canada Ltd. (1971).

[8] E. S. Wood, J. White, A. Nelson, Oxidation behavior of U-Si compounds in air from 25 to $1000^{\circ} \mathrm{C}$, Journal of Nuclear Materials 484 (2017) 245 - 257. doi:http://dx.doi.org/10.1016/j.jnucmat.2016.12.016. URL http://www. sciencedirect. com/science/article/pii/S0022311516310339

[9] Outotec, HSC Chemistry 7.12011.

[10] R. Domagala, T. Wiencek, H. Thresh, U-Si and U-Si-Ai Dispersion Fuel Alloy Development for Research and Test Reactors, Nuclear Technology 62 (3) (1983) 353-360. 
[11] S. Nazaré, Low enrichment dispersion fuels for research and test reactors, Journal of nuclear materials 124 (1984) 14-24.

[12] Y. I. Petrov, Z. Alekseeva, D. Petrov, Phase equilibria in the $\mathrm{U}_{-} \mathrm{U}_{3} \mathrm{Si}_{2}{ }^{-}$ $\mathrm{UAl}_{2}$ system, Journal of nuclear materials 182 (1991) 60-72.

[13] R. Chang-Kyu, P. Su-Il, K. Il-Hiun, Phase formation and growth at interface between $\mathrm{U}_{3} \mathrm{Si}$ and aluminium, Journal of nuclear materials 184 (3) (1991) 161-166.

[14] P. Caillibot, I. Hastings, Simulation of in-reactor swelling in U-3.5 wt\% Si-1.5 wt\% Al by ion bombardment, Journal of Nuclear Materials 59 (3) (1976) 257-262.

[15] Y. S. Kim, Uranium intermetallic fuels (U-Al, U-Si, U-Mo), Comprehensive Nuclear Materials 3 (2012) 391-422.

[16] G. L. Hofman, Crystal structure stability and fission gas swelling in intermetallic uranium compounds, Journal of Nuclear Materials 140 (3) (1986) 256-263.

[17] I. Ansara, B. Grieb, B. Legendre, Z. M. Alekseeva, Ternary Alloys 8 (1993) 292-304.

[18] P. Rogl, G. André, F. Boureé, H. Noël, Magnetic structures of $\mathrm{U}_{3} \mathrm{M}_{2} \mathrm{M}_{3}{ }_{3}$, $\mathrm{M}=\mathrm{Al}, \mathrm{Ga} ; \mathrm{M}^{\prime}=\mathrm{Si}$, Ge: a neutron powder diffraction study, Journal of Magnetism and Magnetic Materials 191 (3) (1999) 291-300.

[19] F. Weitzer, M. Potel, H. Noël, P. Rogl, Crystal Structure and Magnetism of Novel Compounds $\mathrm{U}_{3}\left(\mathrm{M}, \mathrm{M}_{5}\right), \mathrm{M}=\mathrm{Al}$, Ga, $\mathrm{M}=\mathrm{Si}$, Ge, Journal of Solid State Chemistry 111 (2) (1994) 267-275.

[20] A. Dwight, Study of the uranium-aluminum-silicon system, Tech. rep., Argonne National Lab., IL (USA) (1982).

[21] W. Zachariasen, Crystal chemical studies of the 5f-series of elements. VIII. Crystal structure studies of uranium silicides and of $\mathrm{CeSi}_{2}, \mathrm{NpSi}_{2}$, and $\mathrm{PuSi}_{2}$, Acta Crystallographica 2 (2) (1949) 94-99.

[22] A. Andresen, Crystal structure of $\mathrm{U}_{3} \mathrm{O}_{8}$ determined by neutron diffraction, JOURNAL OF INORGANIC \& NUCLEAR CHEMISTRY 7 (1-2) (1958) 169-169. 
${ }_{337}$ [23] B. BELBEOCH, C. PIEKARSKI, P. PERIO, STRUCTURE DE $\mathrm{U}_{4} \mathrm{O}_{9}, \quad$ ACTA CRYSTALLOGRAPHICA 14 (8) (1961) 837-\&. doi:10.1107/S0365110X61002448. 
Table 1: Summary of oxidation results

\begin{tabular}{cccc}
\hline Sample & $\begin{array}{c}\text { Composition assuming } \\
\text { Al volatilization }\end{array}$ & $\begin{array}{c}\text { Onset of breakaway oxidation } \\
{ }^{\circ} \mathrm{C}\end{array}$ & $\begin{array}{c}\text { Terminal oxidation } \\
\text { \% Mass Gain }\end{array}$ \\
\hline \hline $\mathrm{U}$ metal & & 495 & $18\left(18^{*}\right)$ \\
$\mathrm{UO}_{2}$ & & 455 & $4\left(4^{*}\right)$ \\
$\mathrm{U}_{3} \mathrm{Si}_{2}$ & & 384 & $21\left(25^{*}\right)$ \\
$\mathrm{U}_{3} \mathrm{Si}_{1.91} \mathrm{Al}_{0.09}$ & $\mathrm{U}_{3} \mathrm{Si}_{1.92} \mathrm{Al}_{0.12} * *$ & 415 & $21\left(25^{*}\right)$ \\
$\mathrm{U}_{3} \mathrm{Si}_{2} \mathrm{Al}_{0.75}$ & $\mathrm{U}_{3} \mathrm{Si}_{2} \mathrm{Al}_{0.46}$ & 466 & $21\left(26^{*}\right)$ \\
$\mathrm{U}_{3} \mathrm{Si}_{2} \mathrm{Al}_{1.25}$ & $\mathrm{U}_{3} \mathrm{Si}_{2} \mathrm{Al}_{1.17}$ & 523 & $23\left(27^{*}\right)$ \\
$\mathrm{U}_{3} \mathrm{Al}_{2} \mathrm{Si}_{3}$ & $\mathrm{U}_{3} \mathrm{Al}_{2} \mathrm{Si}_{3}$ & 670 & $25\left(32^{*}\right)$ \\
\hline
\end{tabular}

${ }_{340} *$ Theoretical $\%$ mass gain assuming final oxidation products are $\mathrm{U}_{3} \mathrm{O}_{8}$, $341 \quad \mathrm{SiO}_{2}$ and $\mathrm{Al}_{2} \mathrm{O}_{3}$

${ }_{342}^{*} *$ Additional $\mathrm{Al}$ an $\mathrm{Si}$ were incorporated in the initial charge; therefore 343 accounting for the mass loss during arc melting results in an excess of $\mathrm{Al}$ in 344 this composition. 


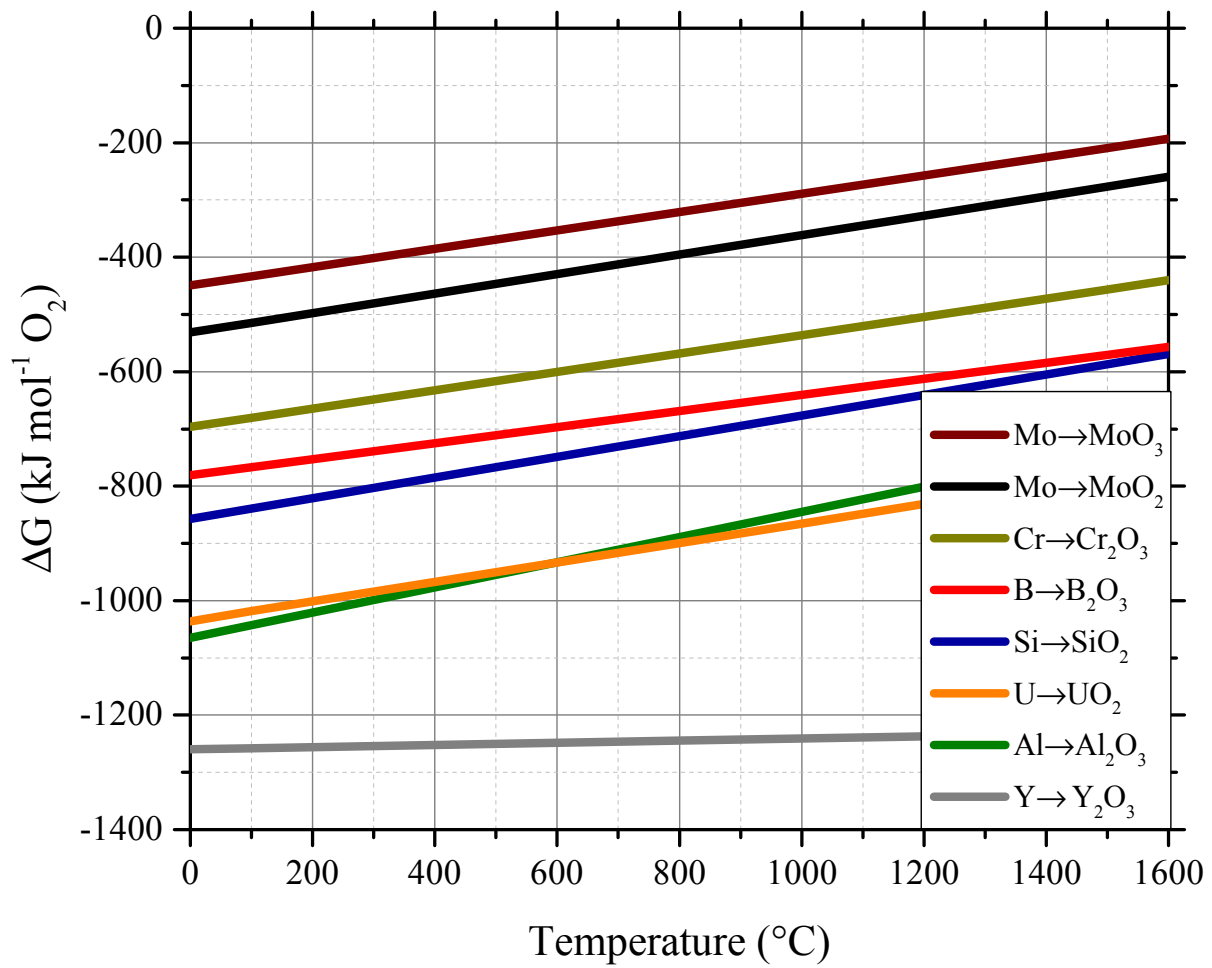

Figure 1: Ellingham diagram from relevant oxides for U-Si oxidation. 


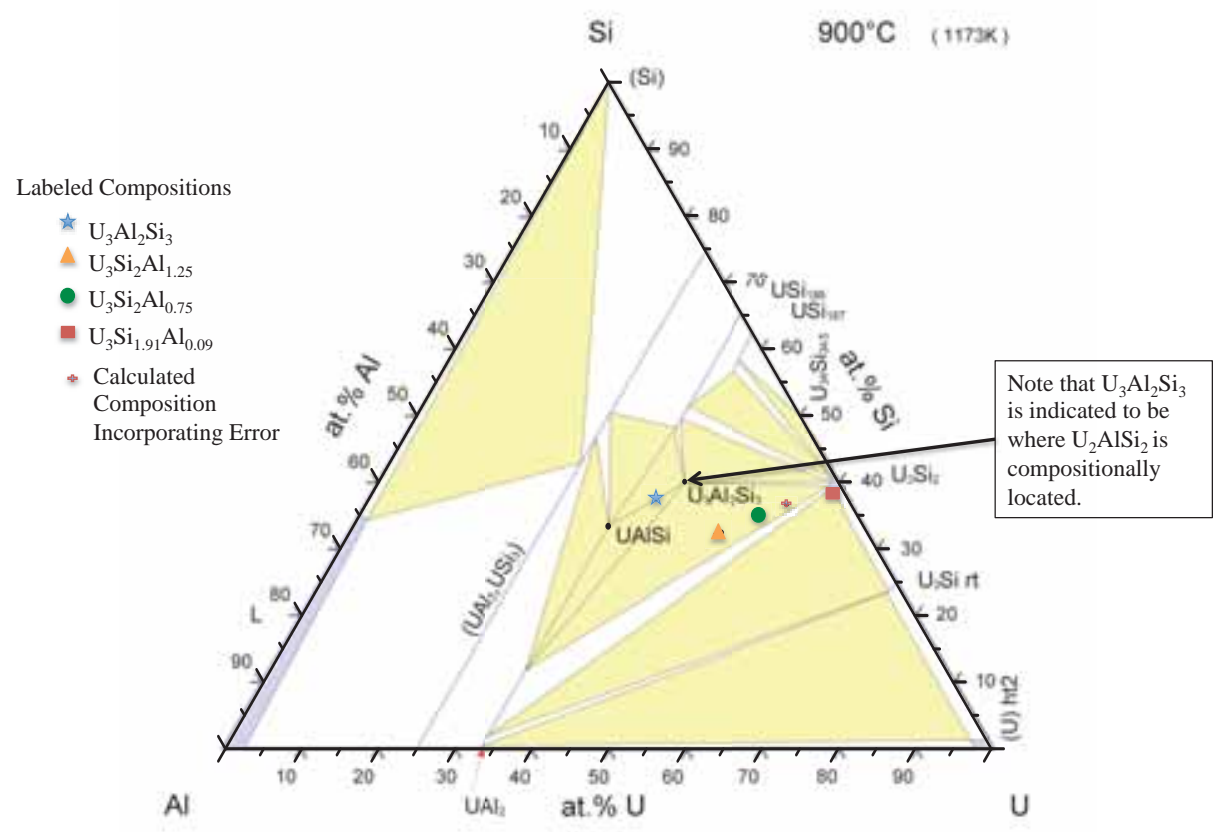

Figure 2: Phase diagram for the U-Si-Al system[17, 18] with the compositions investigated here and labeled along with the error associated with the arcmelting process. 


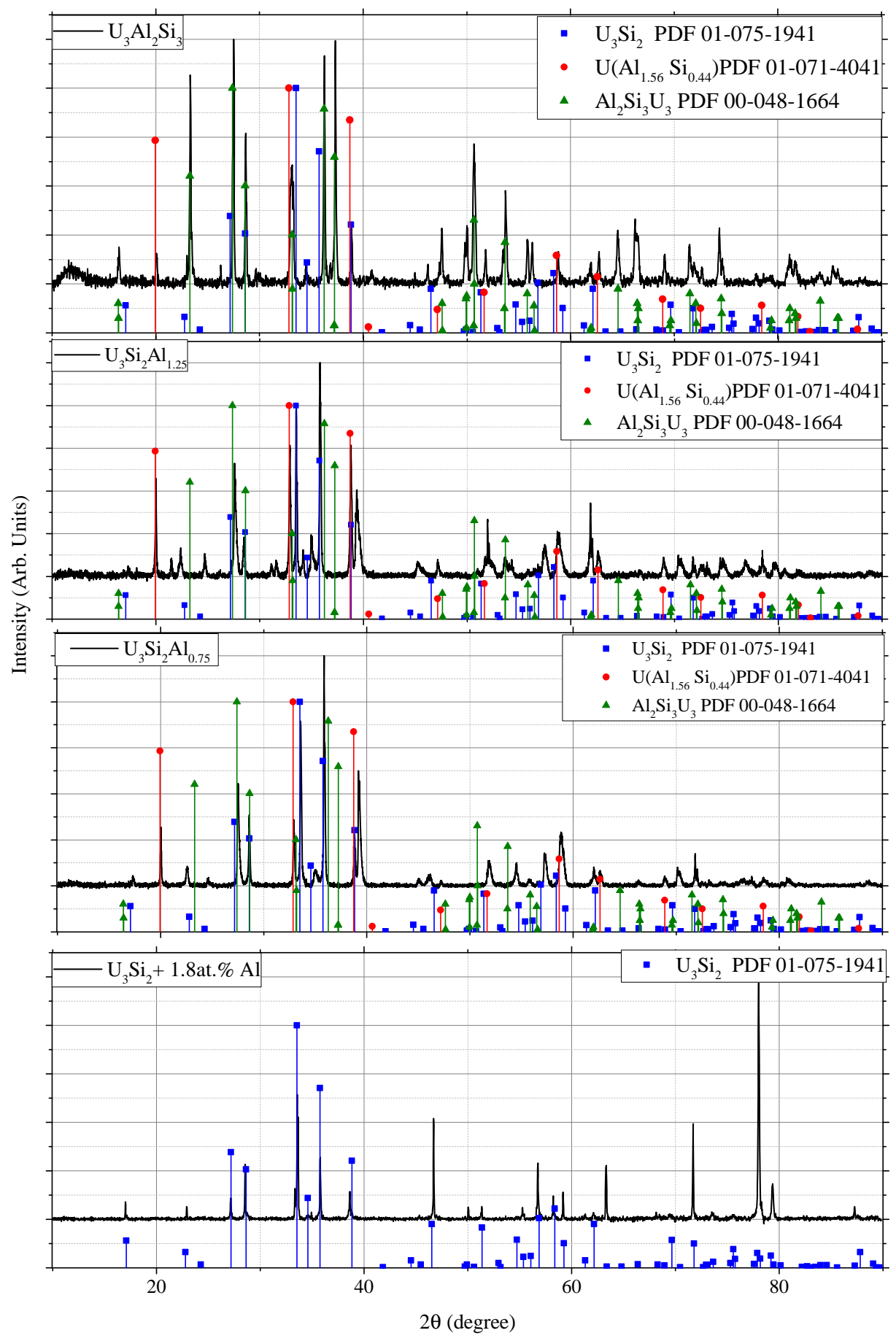

18

Figure 3: X-ray diffraction patterns of the as melted U-Si-Al composition. All but the $\mathrm{U}_{3} \mathrm{Si}_{2}+1.8 \mathrm{at} \% \mathrm{Al}$ is multiphase.[19-21] 

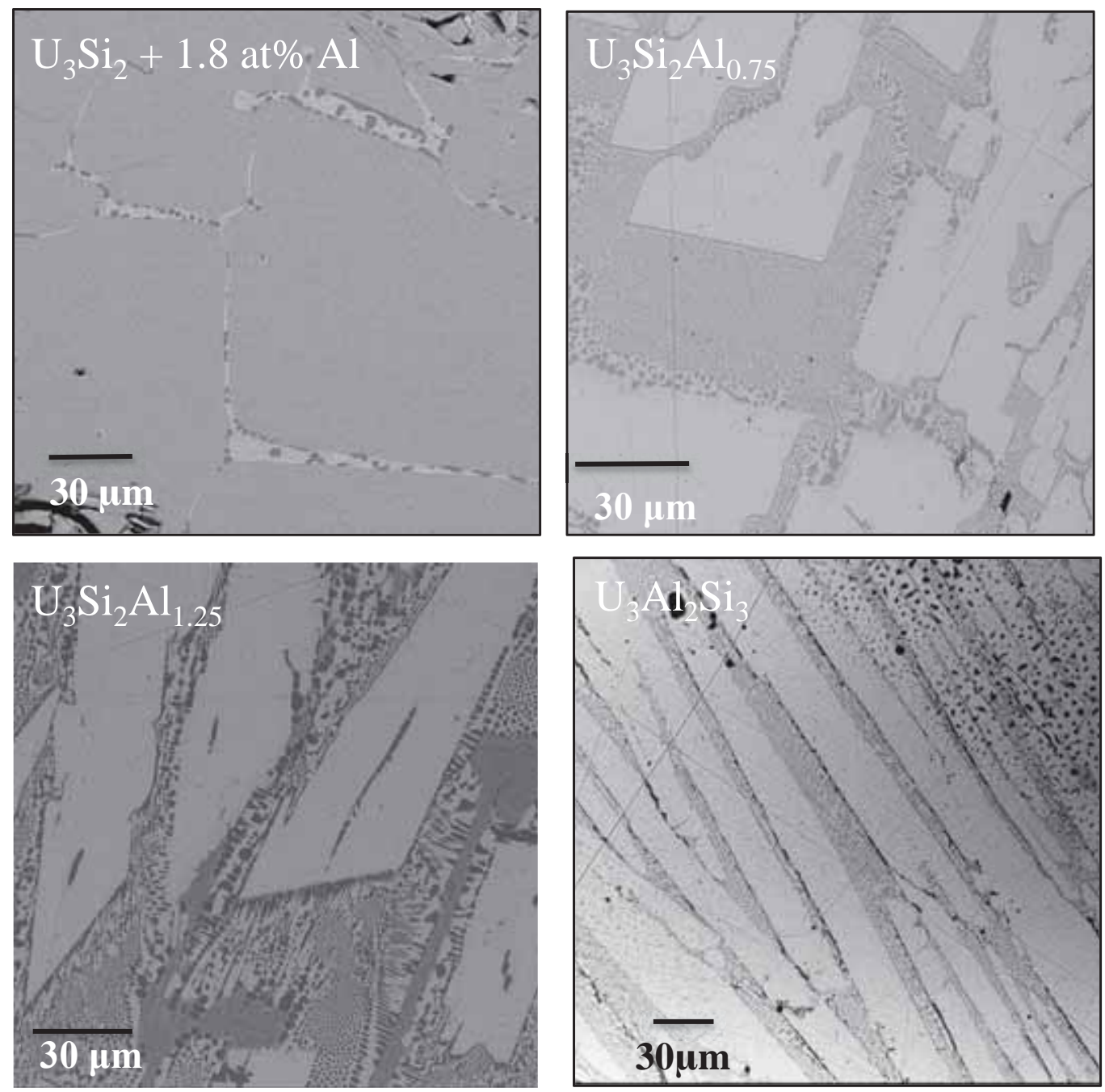

Figure 4: Cross-section backscatter SEM micrographs fo the as melted U-Si-Al compositions. 


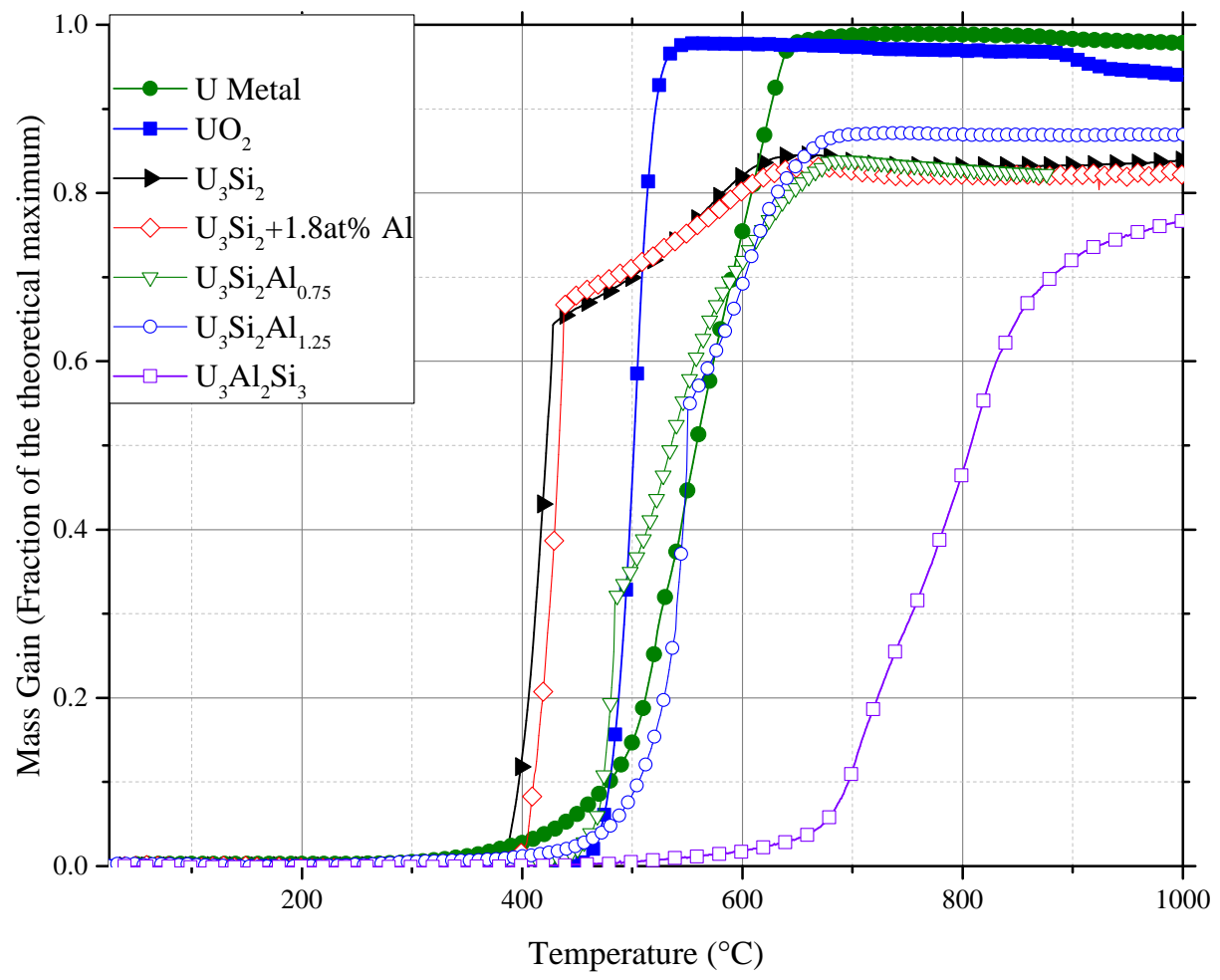

Figure 5: Thermogravimetric data plotted as the fraction of theoretical maximum mass gain for $\mathrm{U}$ metal, $\mathrm{UO}_{2}, \mathrm{U}_{3} \mathrm{Si}_{2}, \mathrm{U}_{3} \mathrm{Si}_{2}+1.8$ at\% $\mathrm{Al}, \mathrm{U}_{3} \mathrm{Si}_{2} \mathrm{Al}_{0.75}, \mathrm{U}_{3} \mathrm{Si}_{2} \mathrm{Al}_{1.25}$, and $\mathrm{U}_{3} \mathrm{Al}_{2} \mathrm{Si}_{3}$ during synthetic air ramp oxidation testing showing a delay in the breakaway oxidation onset with the inclusion of $\mathrm{Al}$. 

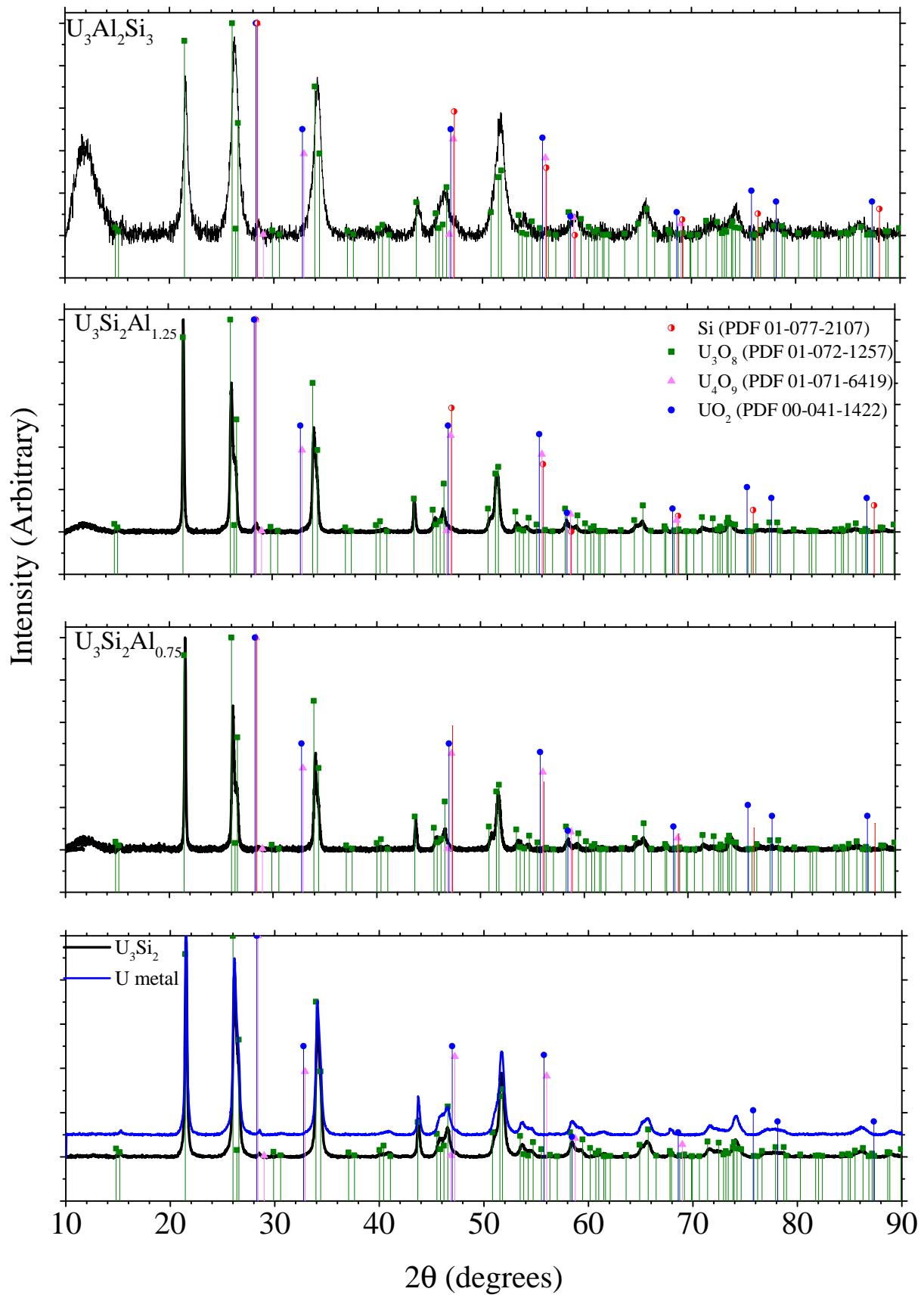

Figure 6: XRD pattern for the oxide products formed during ramp oxidation testing for $\mathrm{U}$ metal, $\mathrm{U}_{3} \mathrm{Si}_{2},[8] \mathrm{U}_{3} \mathrm{Si}_{2} \mathrm{Al}_{0.75}, \mathrm{U}_{3} \mathrm{Si}_{2} \mathrm{Al}_{1.25} 2 \mathrm{And} \mathrm{U}_{3} \mathrm{Al}_{2} \mathrm{Si}_{3} .[22,23]$ 

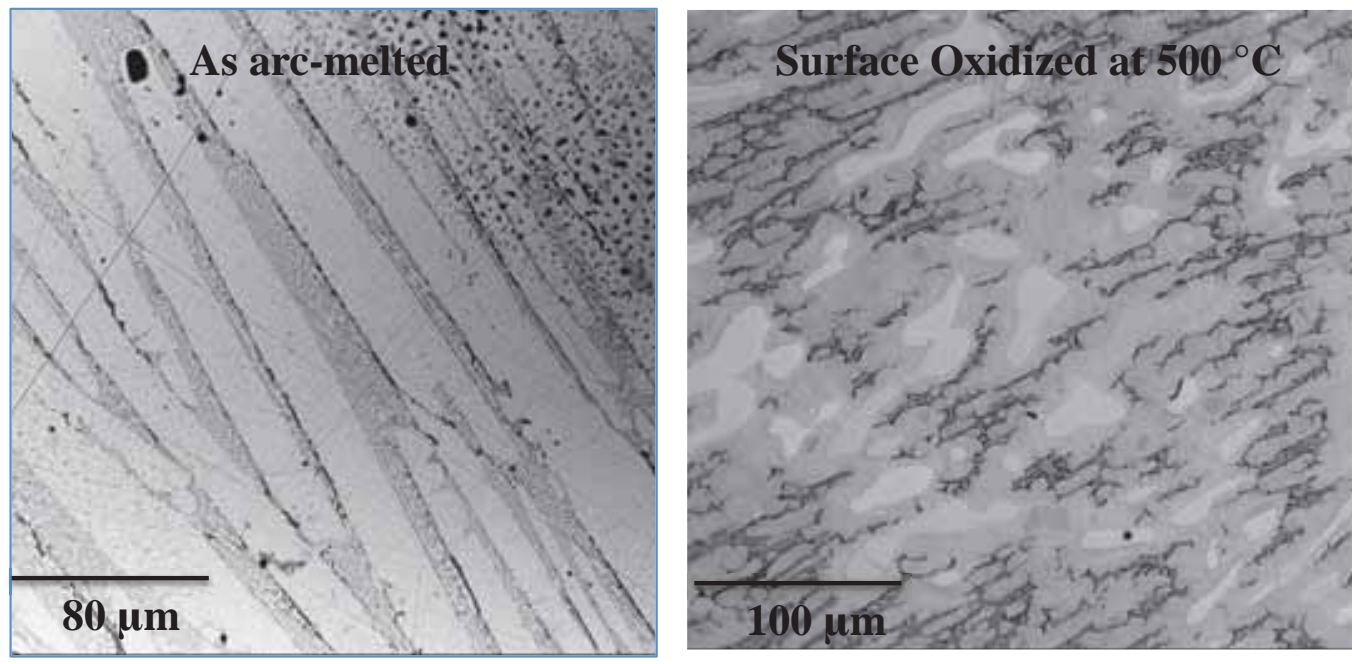

Figure 7: Micrographs of the as-melted $\mathrm{U}_{3} \mathrm{Al}_{2} \mathrm{Si}_{3}$, equilibrium composition (left) and the oxidized surface (right) following $500^{\circ} \mathrm{C}$ exposure to synthetic air
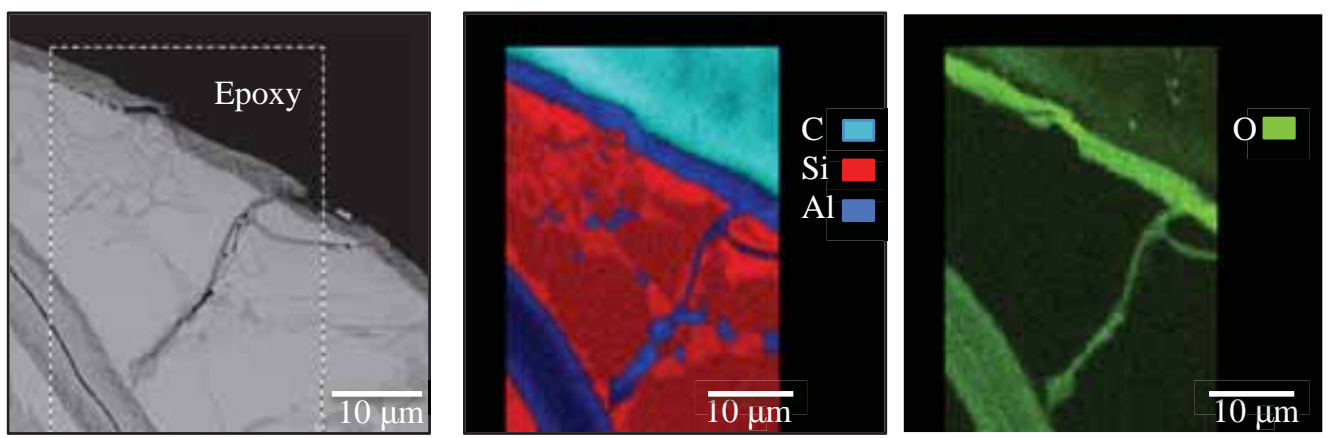

Figure 8: Cross-sectional micrograph of the oxidized $\mathrm{U}_{3} \mathrm{Al}_{2} \mathrm{Si}_{3}$, equilibrium composition (left) and EDS maps of the selected area (middle and right) which display $\mathrm{Al}_{2} \mathrm{O}_{3}$ formation along the edges of the sample and along cracks 